\title{
Optimization OF ARTIFICIAL NEURAL NeTWORK MODEL FOR IMPROVEMENT OF ARTIFICIAL INTELLIGENCE OF MANUALLY DRIVEN BRICK MAKING MACHINE POWERED BY HPFM
}

\author{
P. A. Chandak ${ }^{1}$ and J. P. Modak ${ }^{2}$ \\ ${ }^{1}$ Department of Mechanical Engineering, DMIETR, Wardha (MH), India \\ ${ }^{2}$ Professor Emeritus, Dean (R\&D), PCE, Nagpur(MH), India
}

\begin{abstract}
Considerable development has been done by some authors of this paper towards development of manufacturing process units energized by Human Powered Flywheel Motor (HPFM) as an energy source. This machine system comprises three sub systems namely (i) HPFM (ii) Torsionally Flexible Clutch (TFC) (iii) A Process Unit. Process unit so far tried are mostly rural based such as brick making machine (both rectangular and keyed cross sectioned), Low head water lifting, Wood turning, Wood strips cutting, etc HPFM comprises pedalling system similar to bicycle, a speed rising gear pair and a flywheel big enough such that a young lad of 21-25 years, $165 \mathrm{~cm}$ height, slim structure can pump energy around 30,000 N-m in minutes time. Once such an energy is stored peddling is stopped and a special type of TFC is engaged which very efficiently brings about momentum and energy transfer from flywheel to a process unit. Process unit utilization time upon clutch engagement is 5 to 15 seconds depending on the application. In other word process units needing power of order of $3 \mathrm{hp}$ to $10 \mathrm{hp}$ can be powered by such a machine concept. Experimental data base model is formulated for Human Powered Flywheel Motor Energized Brick Making Machine (HPFMEBMM).

The focus of the present paper is on development of an optimum Artificial Neural Network (ANN) model which will predict the experimental evidences accurately and precisely. The optimisation is acknowledged though variation of various parameters of ANN topology like training algorithm, learning algorithm, size of hidden layer, number of hidden layers, etc while training the network and accepting the best value of that parameter. The paper also discusses the effects and results of variation of various parameters on prediction of network.
\end{abstract}

\section{KEYWORDS}

ANN, Matlab, Manually driven brick making machine. Simulation.

\section{REVIEW OF THE BRICK MAKING MACHINE AND ITS PROCESS UNIT}

\subsection{Working of manually driven Brick making machine}

A manually driven Auger-type brick making [1][3] machine developed by Dr. J. P. Modak is as shown in figure. The operator drives the flywheel (17) though chain (25) and a pair of gears (19, 20). The chain drive is utilized for first stage transmission because the drive is required to be irreversible. This is achieved with the conventional bicycle drive with a free wheel (21). When the flywheel attains sufficient speed, the single jaw clutch $(13,15)$ is engaged. The clutch drives the auger screw through a pair of gears $(9,10)$. The mix fed through hopper (3). A cone (2) connects the drum (30) to the die (1). The cone eliminates the rotary motion of the mix before it 
enters the die. The extracted column is collected in a detachable mould (4). It is lined on the inside by Perspex to provide least resistance to motion of the column. The column is subsequently demoulded by placing it upside down on the platform. The mould is moved horizontally, leaving the column on the platform. About one or two hours after the column is laid on the platform, it becomes stiff enough to be cut by a cutter to form bricks of standard size.

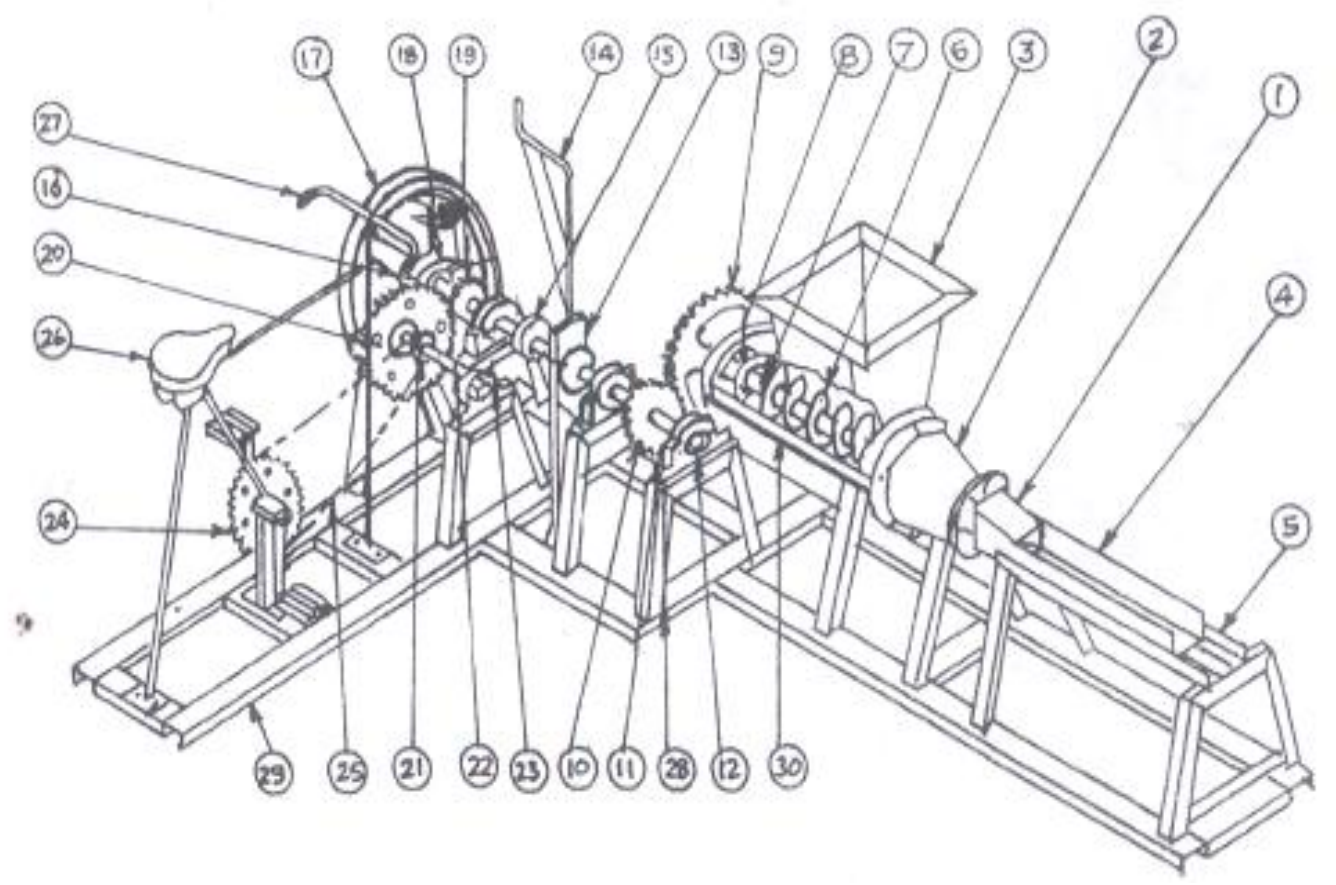

1.DIE, 2.CONE, 3.HOPPER, 4.AL MOULD, 5.MOULDING STAND, 6.CONVEYOR SCREW, 7.CONVEYER SHAFT, 8.HOPPER, 9. GEAR, 10.PINION, 11.PINION SHAFT, 12.BEARING, MOVABLE HALF CLUTCH, 14.CLUTCH LEVER, 15.FIXED HALF CLUTCH, 16.FLYWHEEL SHAFT, 17.FLYWHEEL, 18, BEARING FOR FLYWHEEL, 19.PINION II, 20.GEAR II, 21.FREWHELL, 22.INTERMEDIATE SHAFT, 23.BEARING FOR INTERMEDIATE SHAFT, 24.CRANK GEAR, 25.PINION FOLLOWER CHAIN, 26.DRIVER SEAT, 27.HANDLE, 28.BRACKET, 29.FRAME, 30.CONVEYOR DRUM.

Figure 1. Manually driven Brick Making Machine

The following process variables were involved in the process of experimentation. [1]

Table 1. Process variables and their dimensions

\begin{tabular}{|l|l|l|l|l|}
\hline Sr No. & Description of variables & $\begin{array}{l}\text { Type of } \\
\text { variable }\end{array}$ & Symbol & Dimension \\
\hline 1 & Weight of lime & Independent & WL & ML-1T-2 \\
\hline 2 & Weight of sand & Independent & Ws & ML-1T-2 \\
\hline 3 & Weight of flyash & Independent & Wf & ML-1T-2 \\
\hline 4 & Weight of water & Independent & Ww & ML-1T-2 \\
\hline 5 & Outside diameter of screw & Independent & D1 & L \\
\hline 6 & Inside diameter of screw & Independent & D2 & L \\
\hline 7 & Pitch of Screw & Independent & P & L \\
\hline 8 & Larger Diameter of Cone & Independent & D1 & L \\
\hline 9 & Smaller Diameter of Cone & Independent & D3 & L \\
\hline 10 & Length of cone & Independent & LC & L \\
\hline 11 & Length of die & Independent & LD & L \\
\hline 12 & Moment of Inertia of flywheel & Independent & I & ML2 \\
\hline 13 & Angular velocity of flywheel & Independent & W & T-1 \\
\hline
\end{tabular}


International Journal of Chaos, Control, Modelling and Simulation (IJCCMS) Vol.2, No.3, September 2013

\begin{tabular}{|l|l|l|l|l|}
\hline 14 & Acceleration of due to gravity & Independent & $\mathrm{G}$ & LT-2 \\
\hline 15 & Gear ratio & Independent & $\mathrm{G}$ & - \\
\hline 16 & Length of square side of die & Independent & $\mathrm{S}$ & $\mathrm{L}$ \\
\hline 17 & Strength of brick & Dependent & $\mathrm{Sb}$ & ML-1T-2 \\
\hline 18 & Length of Extruded Brick Column & Dependent & $\mathrm{Lb}$ & $\mathrm{L}$ \\
\hline 19 & Time of Extrusion & Dependent & Te & $\mathrm{T}$ \\
\hline 20 & $\begin{array}{l}\text { Maximum length of Extruded Brick } \\
\text { Column }\end{array}$ & Dependent & Lbm & L \\
\hline 21 & Critical Pressure of Extrusion & Dependent & Pc & ML-1T-2 \\
\hline 22 & Instantaneous Torque on the angular shaft & Dependent & T & ML-1T-2 \\
\hline
\end{tabular}

\subsection{Experimental setup}

The experimental setup [1] basically consists of a manually driven brick making machine with following facilities

- Facility to change die, cone, auger, screw, blades and gears

- Facility to mount the torque meter and to record process torque during extrusion process.

- Facility to mount technogerators to record speeds of flywheel and auger screw.

\subsection{Procedure of Experimentation}

Initially the machine parameters were set as per the plan of experimentation. A homogeneous mix of lime-flyash-sand, in requisite proportion by weight, was prepared by adding suitable amount of water. The mix was soaked for 48 hours and was kept ready for use. To assure thorough mixing, die and cone machine were removed. Sufficient mix was fed into the hopper.

The flywheel was speeded up to $400 \mathrm{rpm}$ and the clutch was engaged. The mix passes out of the barrel and is collected in the collector. The total prepared mix was circulated by using the procedure described above three to four times to assure thorough mixing. Now die and cone were bolted to machine. The mix was fed into the hopper. The flywheel was speeded up to $400 \mathrm{rpm}$ and the clutch was engaged. The extruded brick column was collected in a detachable mould. The brick column was replaced in the hopper. This procedure was repeated five to ten times until an uncracked column of uniform length was obtained. Now the experimental set up was ready to record the observations.

\subsection{Experimental observations and Empirical Model [11]}

The experimental observations were recorded in tabulated form. As the variables involved were high in number dimensionless pi terms were evaluated. And an empirical model was generated to predict the experimental findings. The model was as follows.

$\begin{aligned} \mathrm{Lb} / \mathrm{D} 1 & =0.0043(\mathrm{LD} / \mathrm{D} 1)^{-1.8091} *(\mathrm{D} 12 / \mathrm{IgWf}) \\ & *(\mathrm{P} / \mathrm{D} 1)^{1.3075} *(\mathrm{D} 2 / \mathrm{D} 1)^{0.8313}\end{aligned}$

\section{IDENTIFICATION OF PROBLEM AND SELECTED APPROACH}

The plots are drawn to see the prediction of experimental evidences by the traditional empirical model. The figures 2 to 8 evaluate and compare the results. 
International Journal of Chaos, Control, Modelling and Simulation (IJCCMS) Vol.2, No.3, September 2013

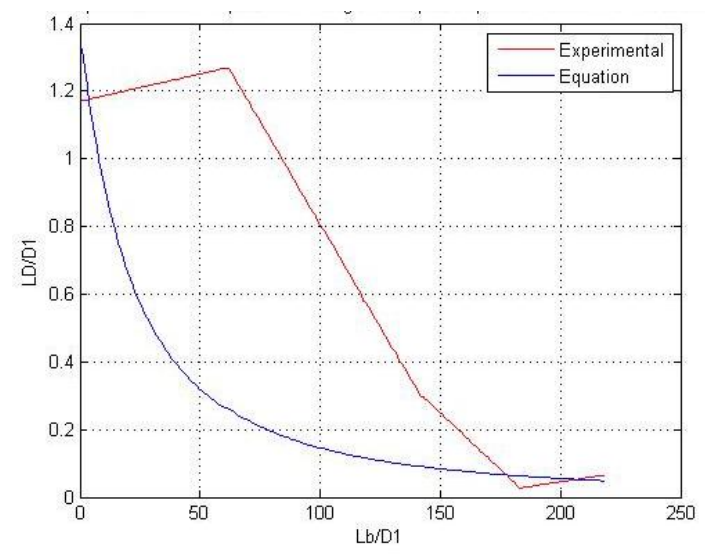

Figure 2: Graph of comparison between experimental observations and equation based prediction for LD/D1 Vs Lb/D1

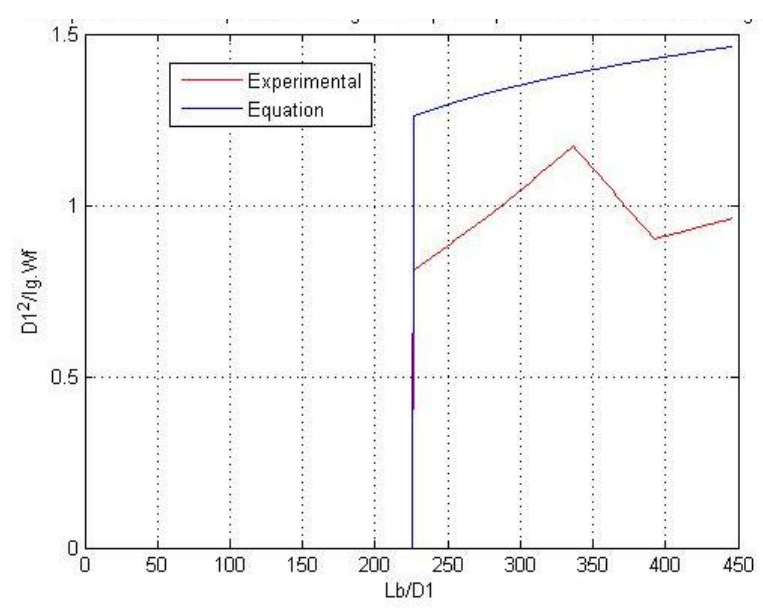

Figure 3: Graph of comparison between experimental observations and equation based prediction for $\left.\mathrm{D} 1^{2} / \mathrm{Ig}\right) \mathrm{Wf} \mathrm{Vs} \mathrm{Lb} / \mathrm{D} 1$

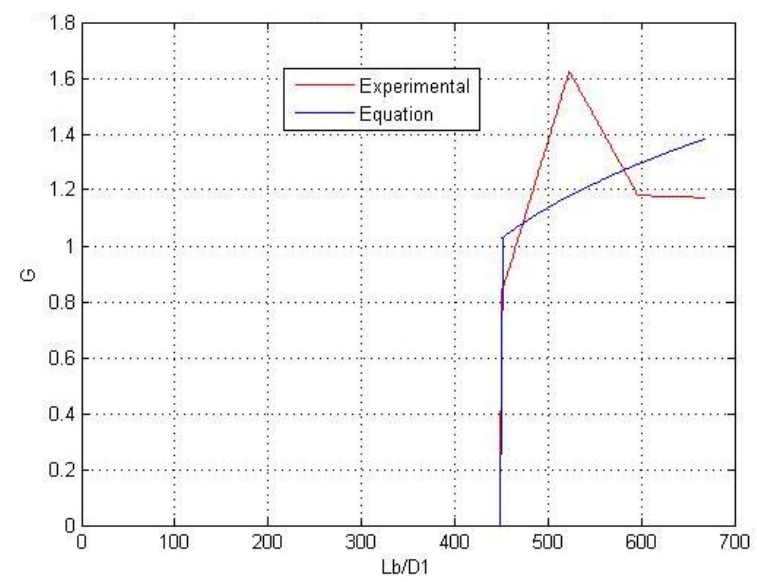

Figure 4: Graph of comparison between experimental observations and equation based prediction for G Vs $\mathrm{Lb} / \mathrm{D} 1$ 
International Journal of Chaos, Control, Modelling and Simulation (IJCCMS) Vol.2, No.3, September 2013

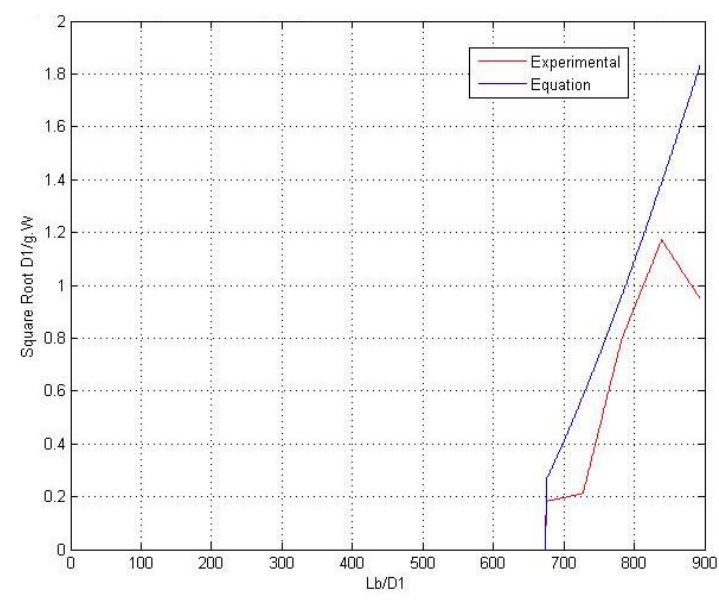

Figure 5: Graph of comparison between experimental observations nd equation based prediction for $\sqrt{ }$ (D1/g). W Vs Lb/D1

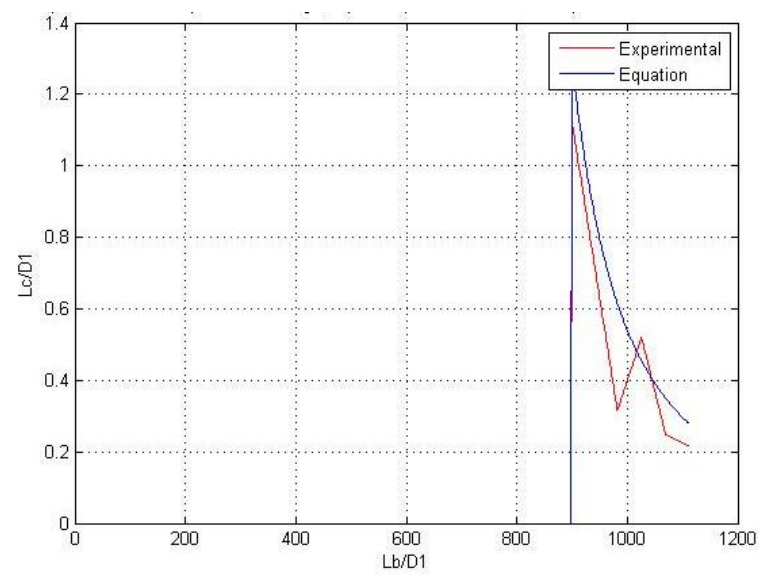

Figure 6: Graph of comparison between experimental observations and equation based prediction for Lc/ D1 Vs Lb/D1

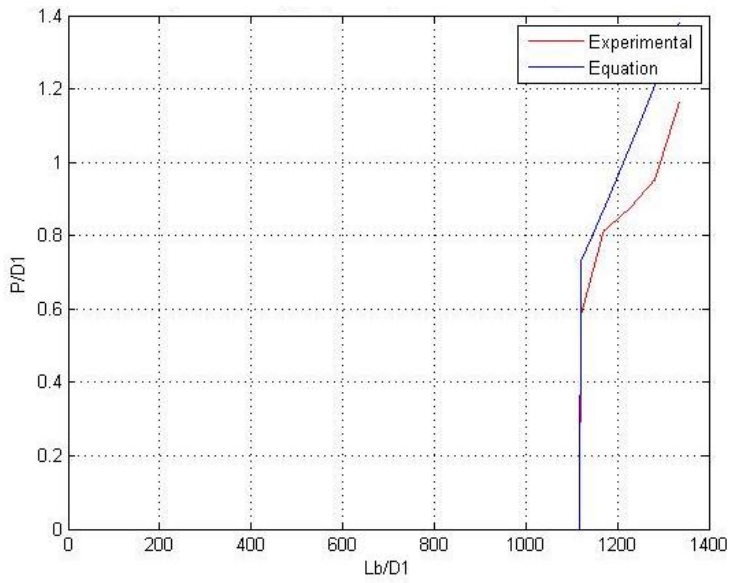

Figure 7: Graph of comparison between experimental observations and equation based prediction for P/ D1 Vs Lb/D1 


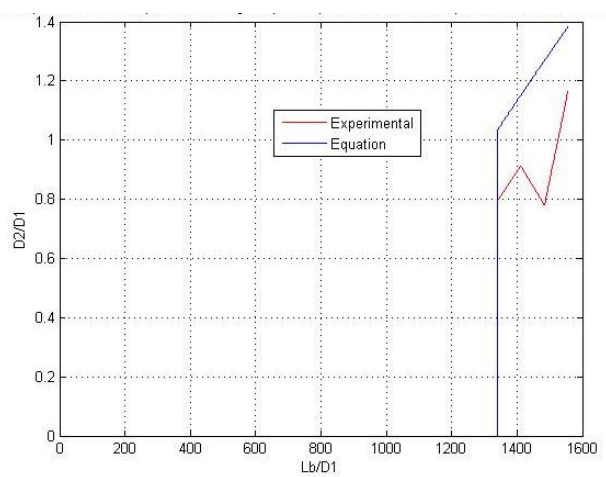

Figure 8: Graph of comparison between experimental observations and equation based prediction for D2/D1 Vs Lb/D1

Figures 2 to 8 clearly shows that the equation is not able to draw a continuous path through the experimental findings. As the previous equation derived stand no more to predict the desired experimental findings, it is forced to go for such a model which will be more reliable and realistic. The percentage error is of the order of 200 to $300 \%$. In view of the fact that independent variables involved are high in numbers, it becomes a very tedious and inaccurate work to build an accurate mathematical model. ANN i.e. Artificial Neural Network has shown its strength in the field of learning and prediction of the desired results when the input variables are high in numbers [7]. Since the equation is not predicting the observed data correctly we cannot rely on the same for predicting the output for the unseen data. On the contrary, ANN model can give more reliable model for the same.

\section{MODIFICATION IN EXISTING DATABASE}

The experimental evidences developed during experimentation were very little in number. As a result experimental database was found to be insufficient for training and validation of the model generated though ANN simulation.

In order to develop ANN model, the existing database was modified and improved in magnitude by manoeuvring plots on the basis of present experimental evidences. The intermediate positions in the plot are positioned and noted [6]. This database generated is as follows.

Table 2. Modified Data

\begin{tabular}{|c|c|c|c|c|c|c|c|c|}
\hline \multirow{2}{*}{$\begin{array}{l}\text { Sr. } \\
\text { No. }\end{array}$} & \multicolumn{7}{|c|}{ Independent Variables } & \multirow{2}{*}{$\begin{array}{l}\text { Dependent } \\
\text { Variables } \\
\text { Lb / D1 }\end{array}$} \\
\hline & LD/D1 & D12/Ig.Wf & $\mathbf{G}$ & $\sqrt{(\text { D1/g).W }}$ & $\begin{array}{l}\text { Lc/ } \\
\text { D1 }\end{array}$ & $\begin{array}{l}\text { P/ } \\
\text { D1 }\end{array}$ & D2 / D1 & \\
\hline 1 & 0.2 & 3.7 & 4.5 & 9.19 & 0.5 & 0.24 & 0.4 & 1.174 \\
\hline$\downarrow$ & $\downarrow$ & $\downarrow$ & $\downarrow$ & $\downarrow$ & $\downarrow$ & $\downarrow$ & $\downarrow$ & $\downarrow$ \\
\hline 240 & 0.5 & 2.102 & 4.5 & 9.19 & 0.5 & 0.24 & 0.4 & 0.854 \\
\hline$\downarrow$ & $\downarrow$ & $\downarrow$ & $\downarrow$ & $\downarrow$ & $\downarrow$ & $\downarrow$ & $\downarrow$ & $\downarrow$ \\
\hline 550 & 0.5 & 3.7 & 2.867 & 9.19 & 0.5 & 0.24 & 0.4 & 1.455 \\
\hline$\downarrow$ & $\downarrow$ & $\downarrow$ & $\downarrow$ & $\downarrow$ & $\downarrow$ & $\downarrow$ & $\downarrow$ & $\downarrow$ \\
\hline 710 & 0.5 & 3.7 & 4.5 & 2.841 & 0.5 & 0.24 & 0.4 & 0.203 \\
\hline$\downarrow$ & $\downarrow$ & $\downarrow$ & $\downarrow$ & $\downarrow$ & $\downarrow$ & $\downarrow$ & $\downarrow$ & $\downarrow$ \\
\hline 912 & 0.5 & 3.7 & 4.5 & 9.19 & 0.4391 & 0.24 & 0.4 & 0.995 \\
\hline$\downarrow$ & $\downarrow$ & $\downarrow$ & $\downarrow$ & $\downarrow$ & $\downarrow$ & $\downarrow$ & $\downarrow$ & $\downarrow$ \\
\hline 1555 & 0.5 & 3.7 & 4.5 & 9.19 & 0.5 & 0.24 & 0.39795 & 1.157 \\
\hline
\end{tabular}




\section{FORMULATION AND IMPLEMENTATION OF SEQUENTIAL MODELLING EVALUATION}

Modelling a system through ANN simulation involves use of ANN parameters appropriately. A topology is nothing but the complete architecture of network formed through the use of ANN parameters [9]. The ANN parameters should be varied systematically in an attempt to identify best topology for a specified problem. The number of layers was restricted to two as the variables involved were high in number. A table for evaluation of modelling technique is formed as below [5]. The shaded column indicates the variation of that particular parameter and shaded row shows the slandered value of that parameter.

Table 3. Table of sequential modelling evaluation

\begin{tabular}{|c|c|c|c|c|c|c|}
\hline \multirow{2}{*}{$\begin{array}{c}\text { Program } \\
\text { Number }\end{array}$} & \multirow{2}{*}{$\begin{array}{c}\text { Hidden } \\
\text { layer } \\
\text { Size }\end{array}$} & \multirow{2}{*}{$\begin{array}{c}\text { Type of } \\
\text { Training } \\
\text { Function }\end{array}$} & \multirow{2}{*}{$\begin{array}{l}\text { Performance } \\
\text { Function }\end{array}$} & \multicolumn{2}{|c|}{$\begin{array}{l}\text { Types of transfer } \\
\text { function }\end{array}$} & \multirow{2}{*}{$\begin{array}{c}\text { Type of } \\
\text { Learning } \\
\text { Algorithm }\end{array}$} \\
\hline & & & & Layer1 & Layer2 & \\
\hline P1 & 20 & trainlm & mse & logsig & purelin & learngd \\
\hline P2 & 100 & trainlm & mse & logsig & purelin & learngd \\
\hline P3 & 200 & trainlm & mse & logsig & purelin & learngd \\
\hline P4 & 100 & trainb & mse & logsig & purelin & learngd \\
\hline P5 & 100 & trainbfg & mse & logsig & purelin & learngd \\
\hline P6 & 100 & trainbr & mse & logsig & purelin & learngd \\
\hline P7 & 100 & trainc & mse & logsig & purelin & learngd \\
\hline P8 & 100 & trainlm & mae & logsig & purelin & learngd \\
\hline P9 & 100 & trainlm & sse & logsig & purelin & learngd \\
\hline P10 & 100 & trainlm & sse & tansig & purelin & learngd \\
\hline P11 & 100 & trainlm & sse & logsig & purelin & learngd \\
\hline P12 & 100 & trainlm & sse & logsig & hardlim & learngd \\
\hline P13 & 100 & trainlm & sse & logsig & tansig & learngd \\
\hline P14 & 100 & trainlm & sse & tansig & logsig & learngd \\
\hline P15 & 100 & trainlm & sse & tansig & satlin & learngd \\
\hline P16 & 100 & trainlm & sse & logsig & satlin & learngd \\
\hline P17 & 100 & trainlm & sse & logsig & poslin & learngd \\
\hline P18 & 100 & trainlm & sse & logsig & tansig & learncon \\
\hline P19 & 100 & trainlm & sse & logsig & tansig & learngd \\
\hline P20 & 100 & trainlm & sse & logsig & tansig & learnh \\
\hline P21 & 100 & trainlm & sse & logsig & tansig & learnk \\
\hline
\end{tabular}

The ANN parameters like hidden layer size, Training algorithm, performance function, transfer functions of layers, learning Algorithm are decided to vary in order to see its effect over the predication of model. Every parameter posses its diversified standard values out of which some are chosen and their effects are observed after and during training. The table 3 shows the program 
International Journal of Chaos, Control, Modelling and Simulation (IJCCMS) Vol.2, No.3, September 2013

number and respected value of each parameter. For each case of a program one parameter is varied and other parameters were allocated some constant standard value.

The training for all programs are carried and results were plotted to see the outcome. The training with so many parameters gives fantastic diversified results which are presented in graphical form as follows.

\section{GRAPHICAL REPRESENTATION OF RESULTS AFTER TRAINING}

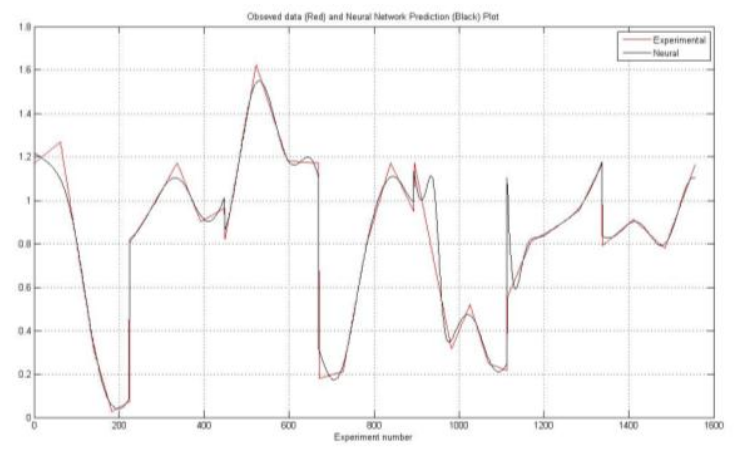

Figure 9: Neural response with 20 Neurons

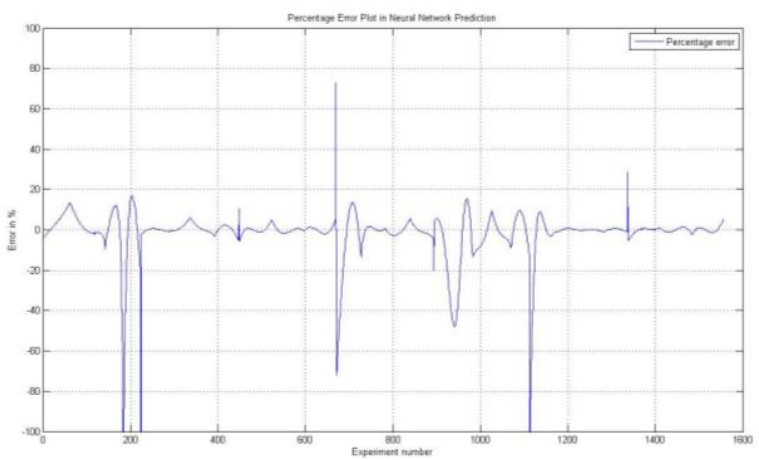

Figure 10: Percentage error with 20 neurons

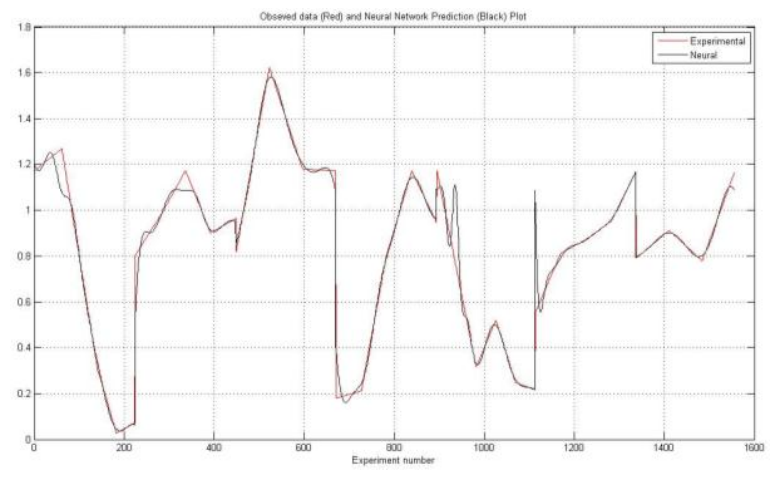

Figure 11: Neural response with 100 Neurons 
International Journal of Chaos, Control, Modelling and Simulation (IJCCMS) Vol.2, No.3, September 2013

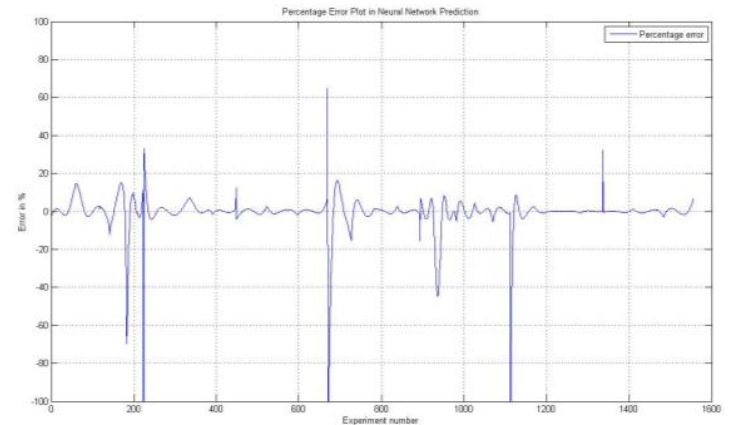

Figure 12: Percentage error with 100 Neurons

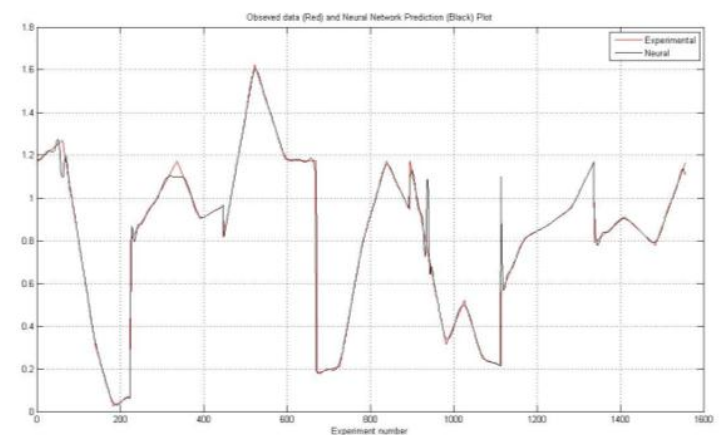

Figure 13: Neural response with 200 Neurons

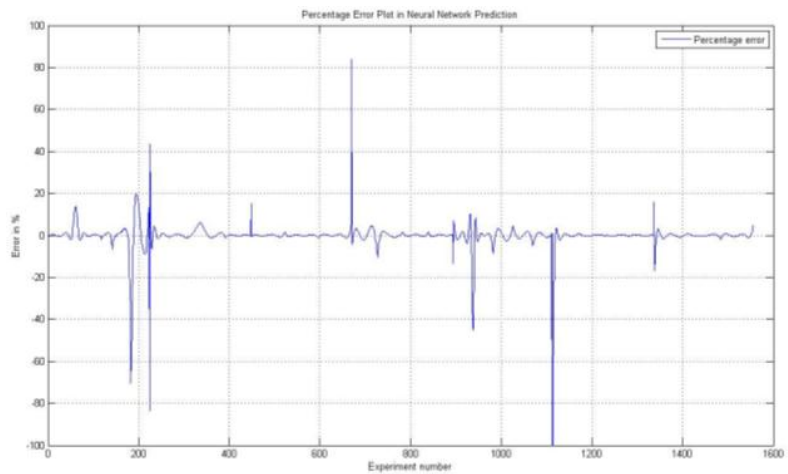

Figure 14: Percentage error with 200 Neurons

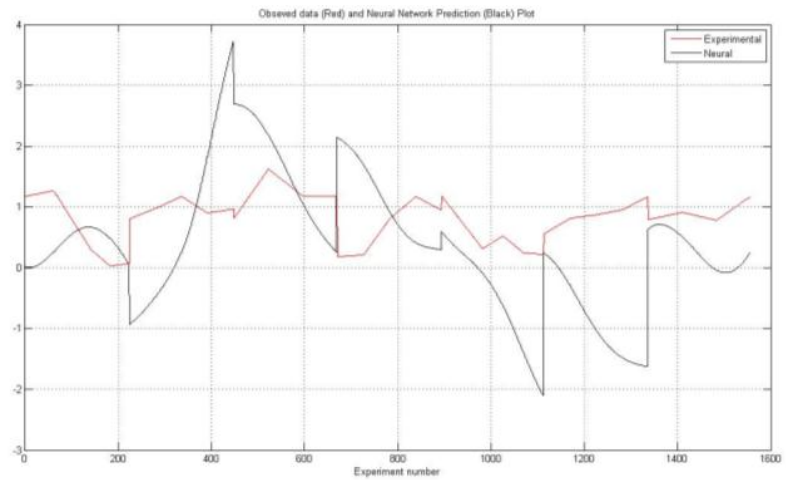

Figure 15: Neural response with training Function "trainb" 
International Journal of Chaos, Control, Modelling and Simulation (IJCCMS) Vol.2, No.3, September 2013

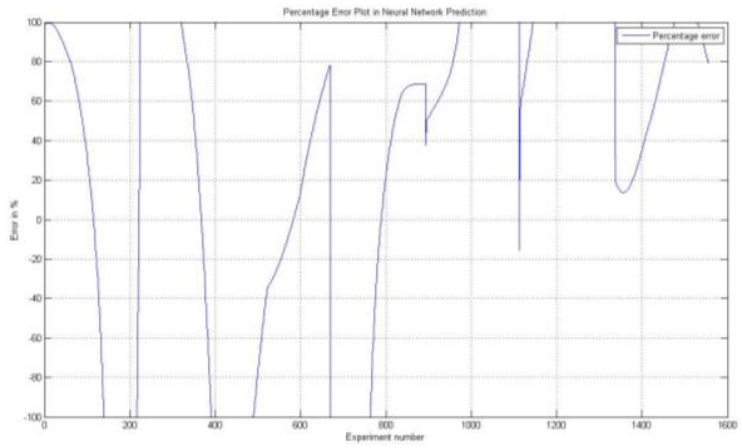

Figure 16: Percentage error with training Function "trainb"

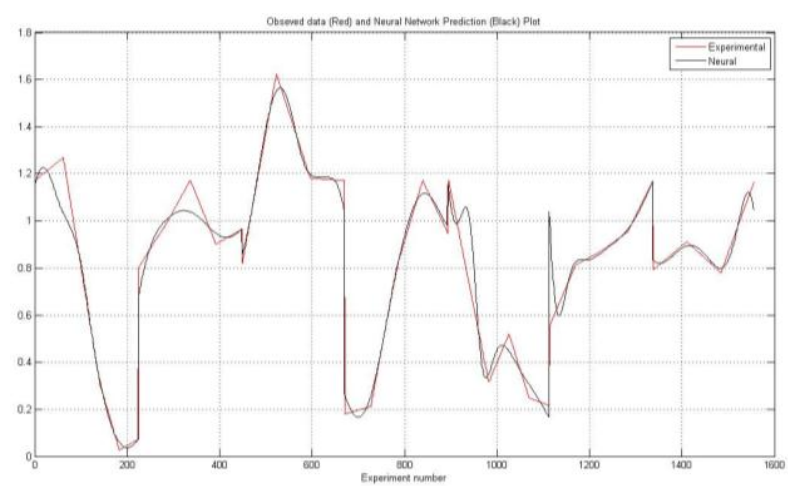

Figure 17: Neural response with training Function "trainbfg"

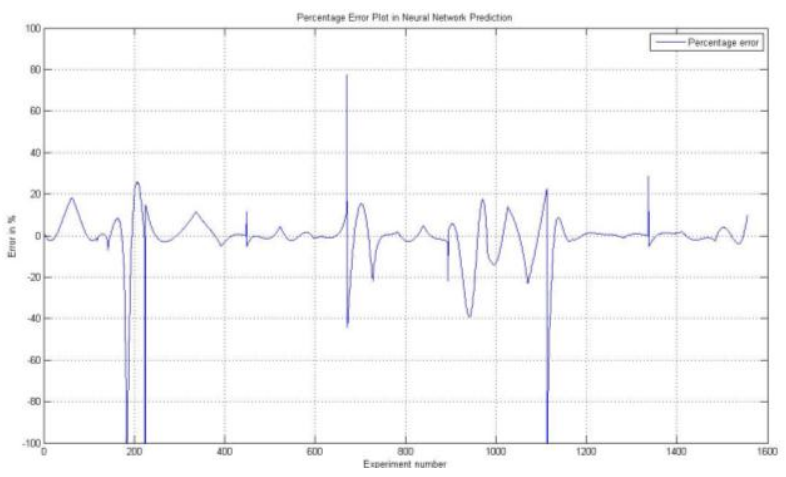

Figure 18: Percentage error with training Function "trainbfg"

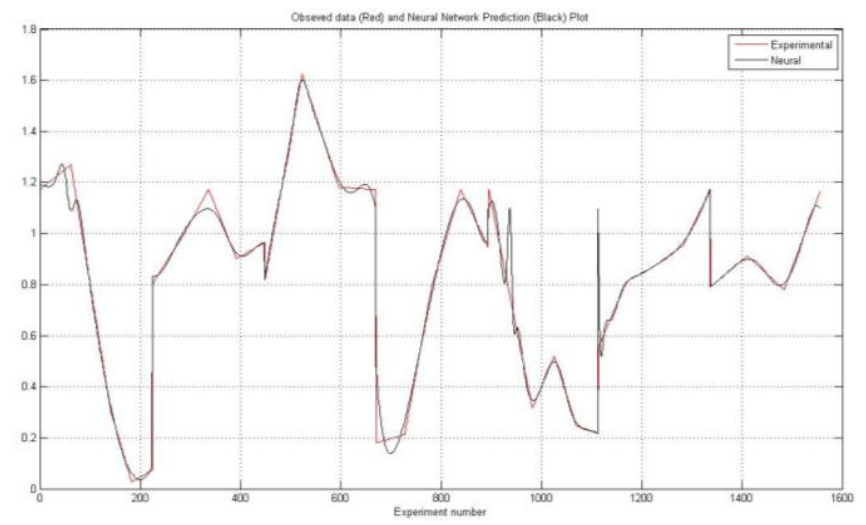

Figure 19: Neural response with training Function "trainbr" 
International Journal of Chaos, Control, Modelling and Simulation (IJCCMS) Vol.2, No.3, September 2013

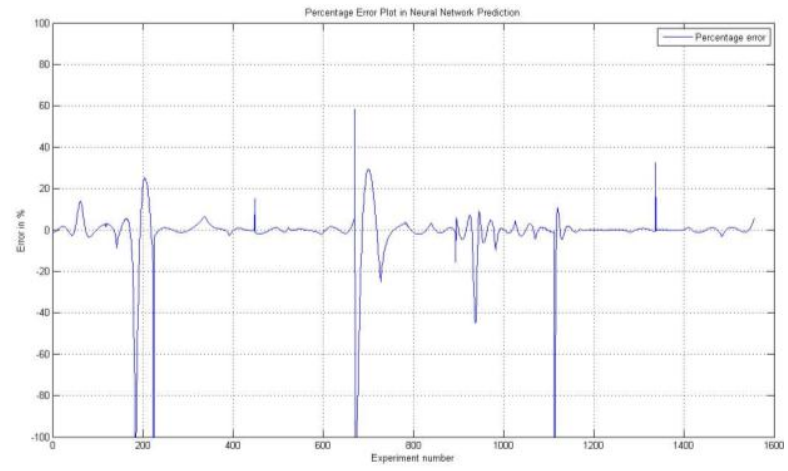

Figure 20: Percentage error with training Function "trainbr"

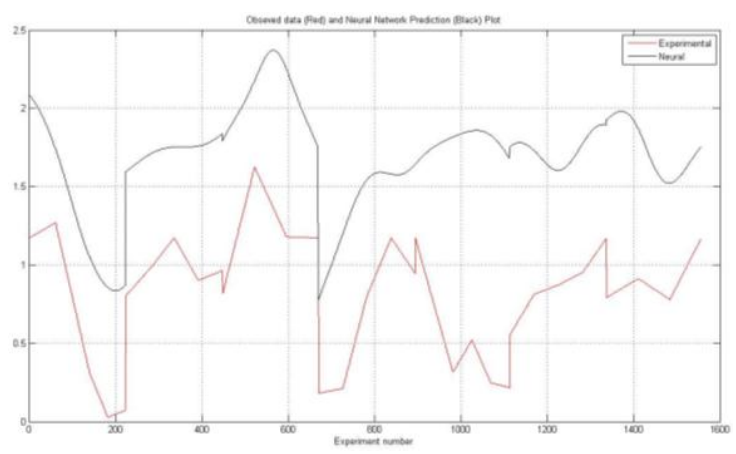

Figure 21: Neural response with training Function "trainc"

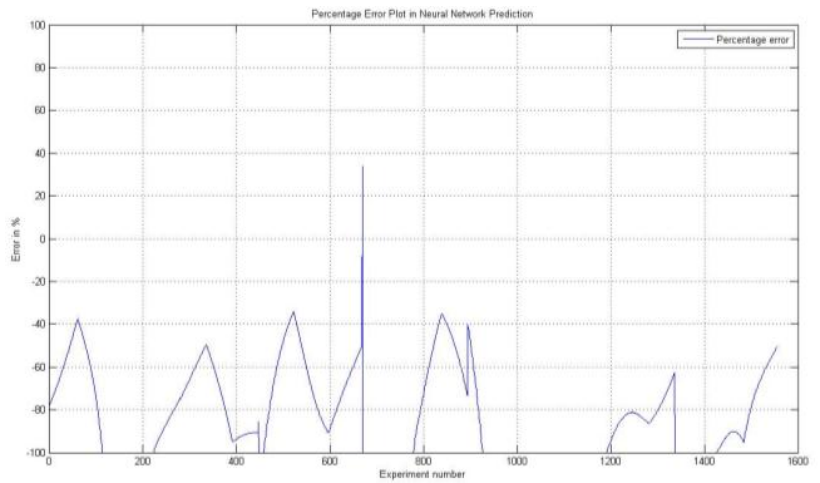

Figure 22: Percentage error with training Function trainc"

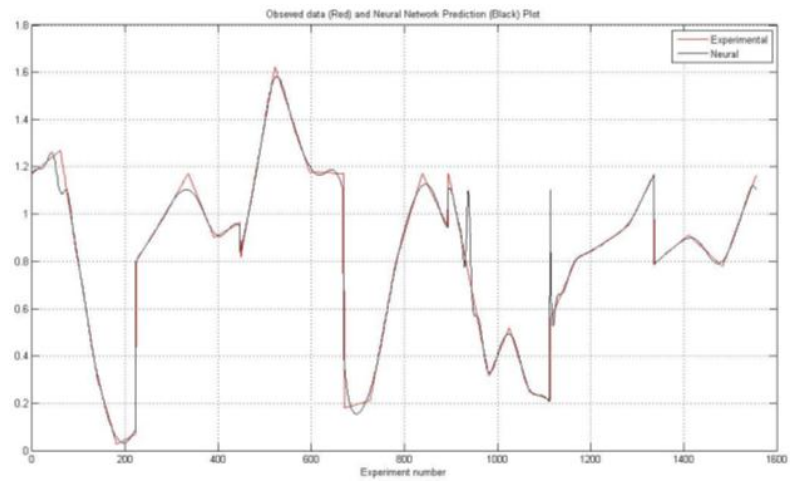

Figure 23: Neural response with performance Function "mae" 
International Journal of Chaos, Control, Modelling and Simulation (IJCCMS) Vol.2, No.3, September 2013

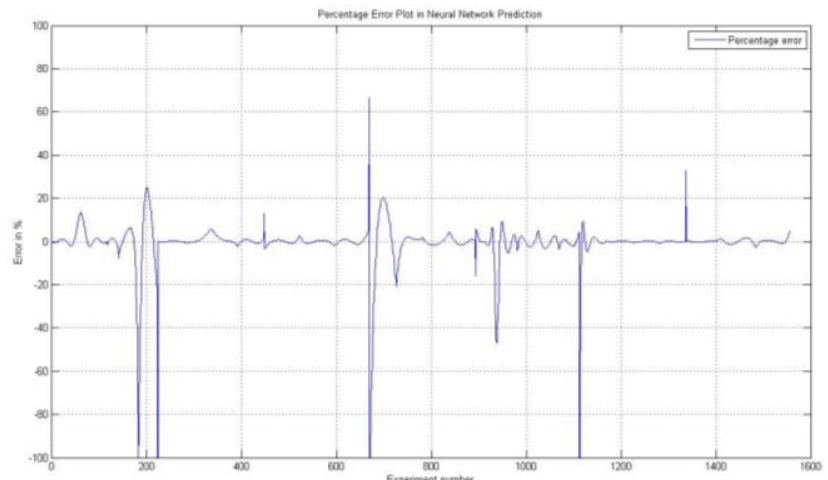

Figure 24: Percentage error with performance Function "mae"

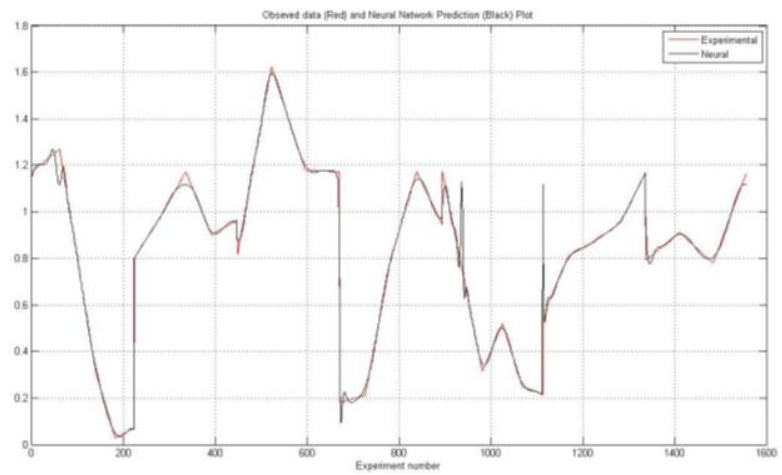

Figure 25: Neural response with performance Function "sse"

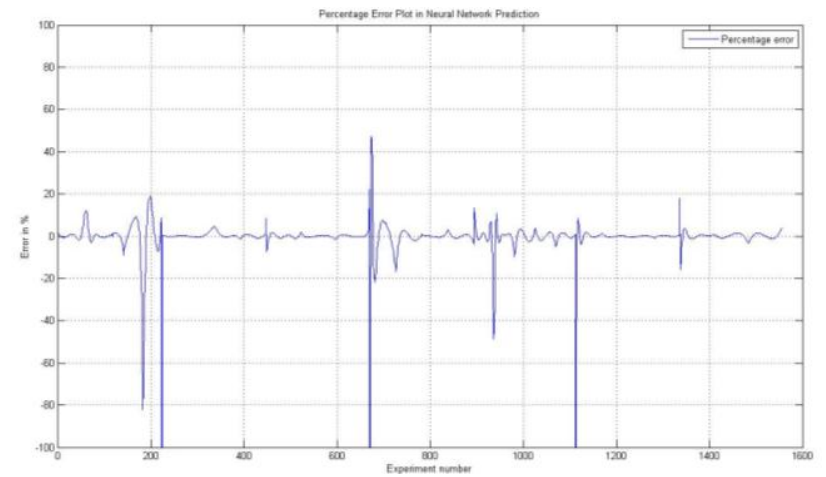

Figure 26: Percentage error with performance Function "sse"

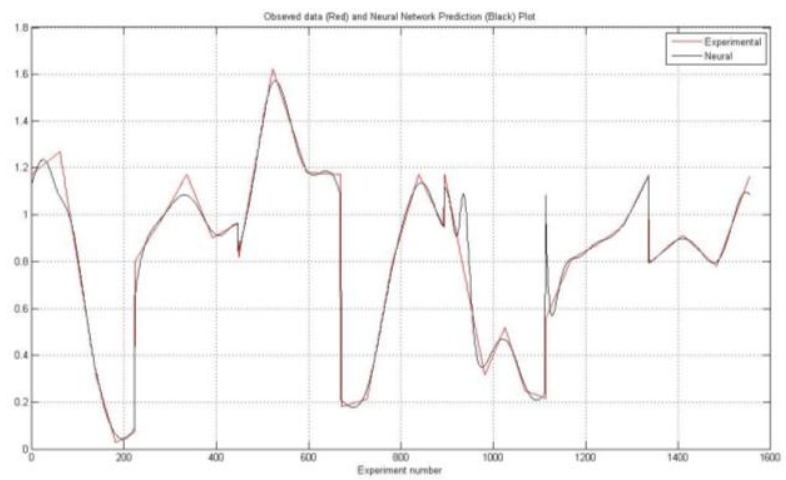

Figure 27: Neural response with layer transfer Function "tansig, purelin" 
International Journal of Chaos, Control, Modelling and Simulation (IJCCMS) Vol.2, No.3, September 2013

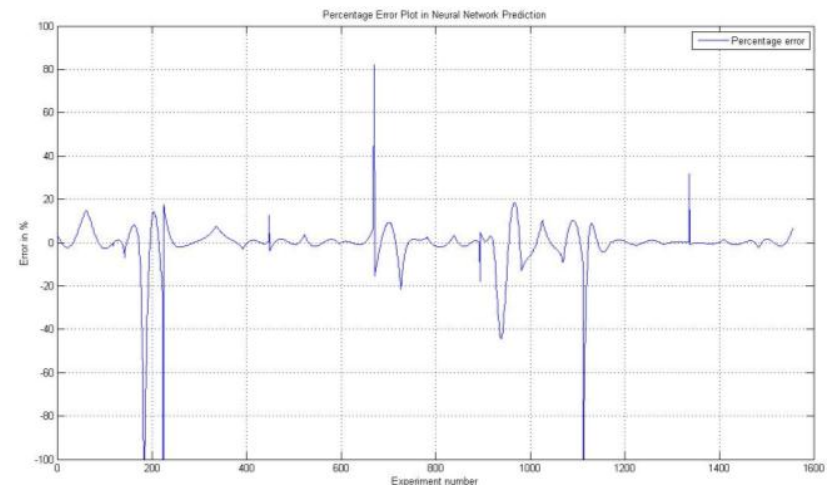

Figure 28: Percentage error with layer transfer Function "tansig, purelin"

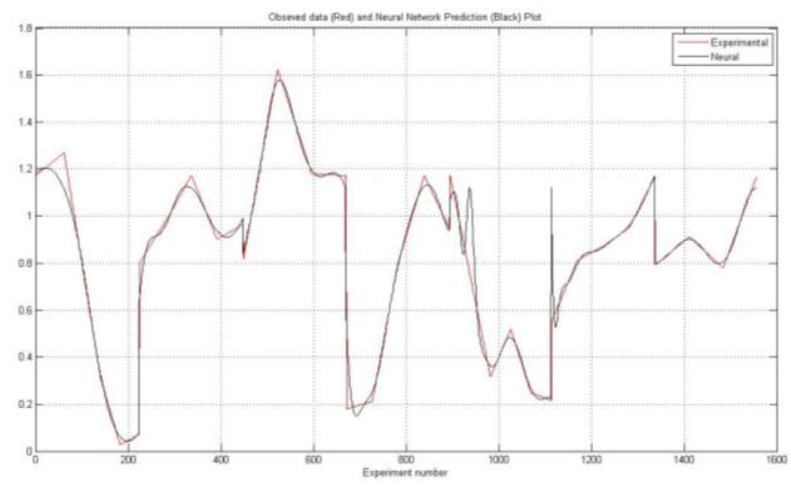

Figure 29: Neural response with layer transfer Function "logsig, purelin"

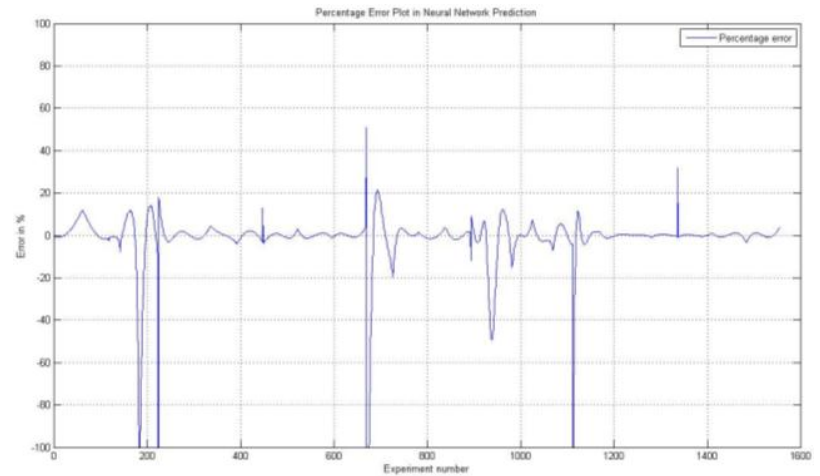

Figure 30: Percentage error with layer transfer Function “logsig, purelin”

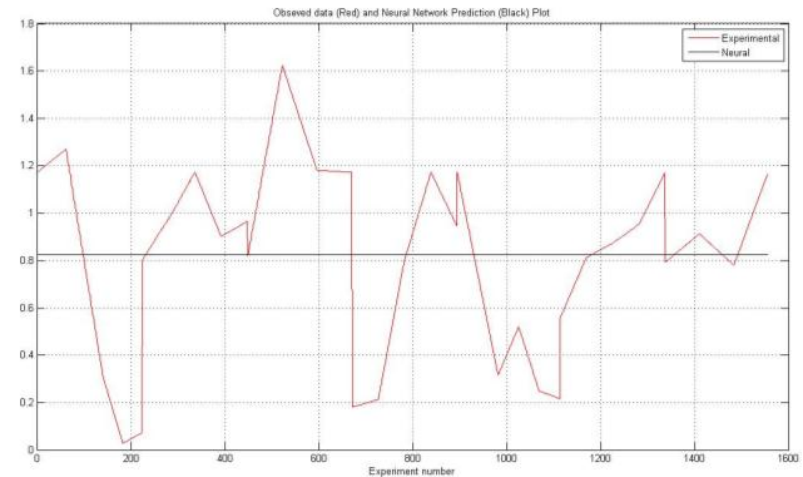

Figure 31: Neural response with layer transfer Function "logsig, hardlim" 
International Journal of Chaos, Control, Modelling and Simulation (IJCCMS) Vol.2, No.3, September 2013

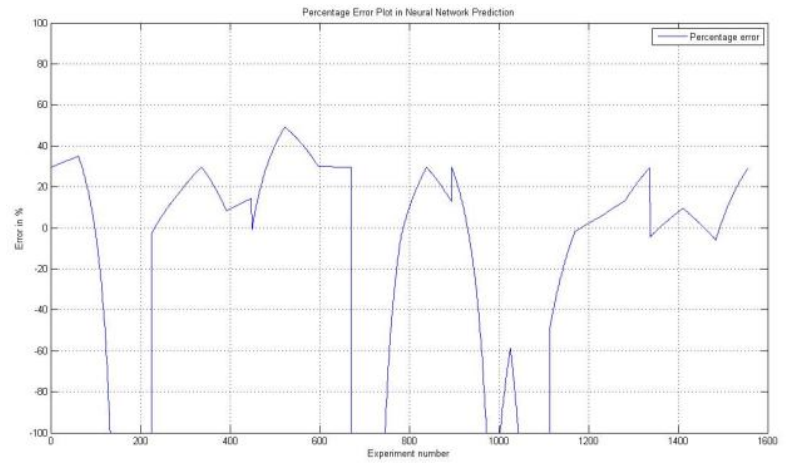

Figure 32: Percentage error with layer transfer Function "logsig, hardlim"

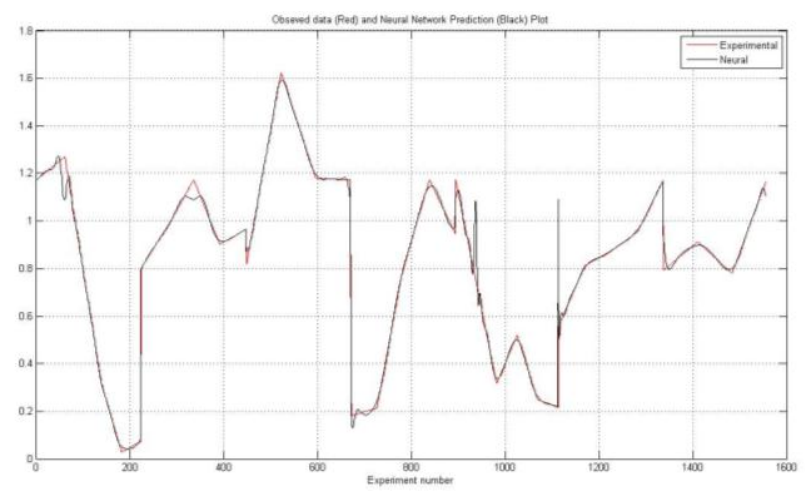

Figure 33: Neural response with layer transfer Function "logsig, tansig"

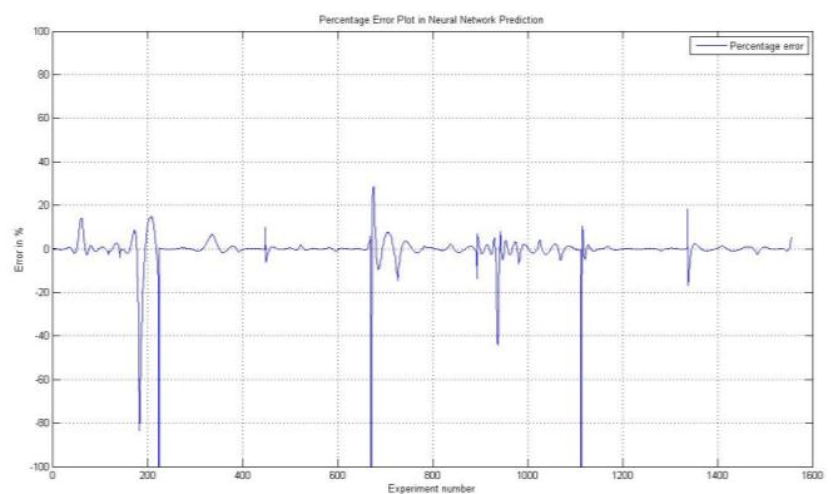

Figure 34: Percentage error with layer transfer Function "logsig, tansig”

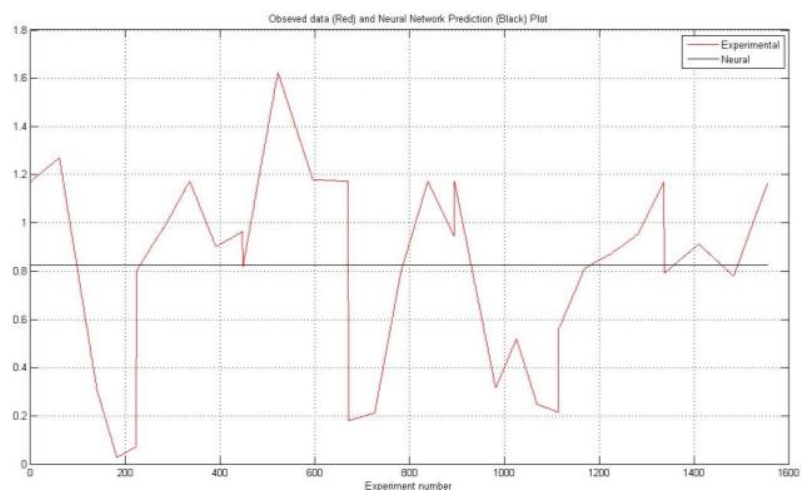

Figure 35: Neural response with layer transfer Function “tansig, logsig” 
International Journal of Chaos, Control, Modelling and Simulation (IJCCMS) Vol.2, No.3, September 2013

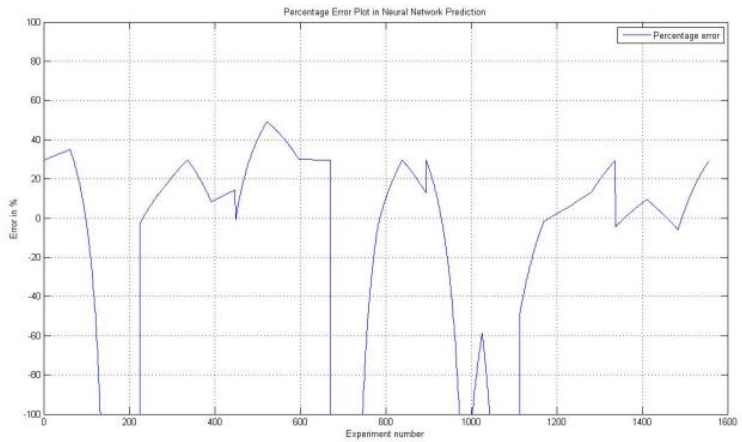

Figure 36: Percentage error with layer transfer Function "tansig, logsig"

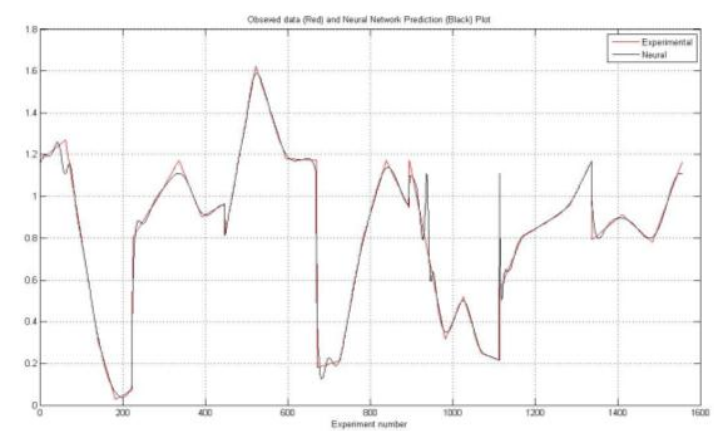

Figure 37: Neural response with layer transfer Function "tansig, satlin"

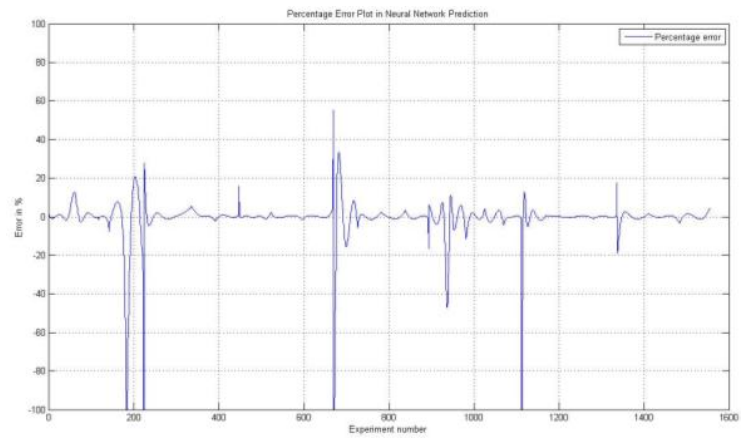

Figure 38: Percentage error with layer transfer Function "tansig, satlin”

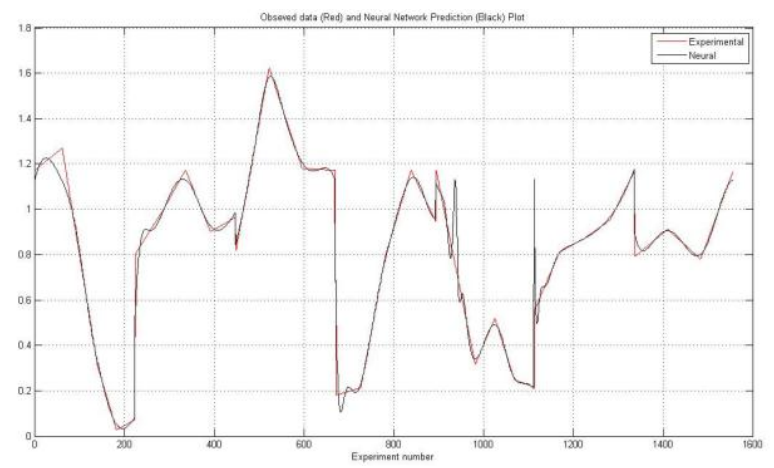

Figure 39: Neural response with layer transfer Function "tansig, purlin" 
International Journal of Chaos, Control, Modelling and Simulation (IJCCMS) Vol.2, No.3, September 2013

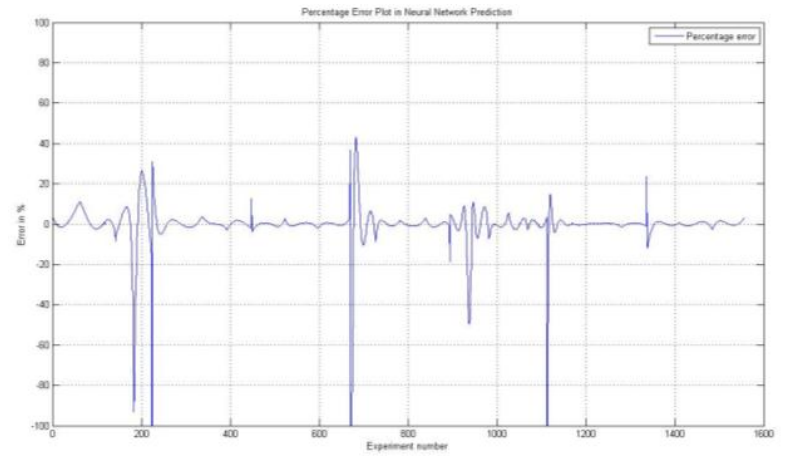

Figure 40: Percentage error with layer transfer Function "tansig, purlin"

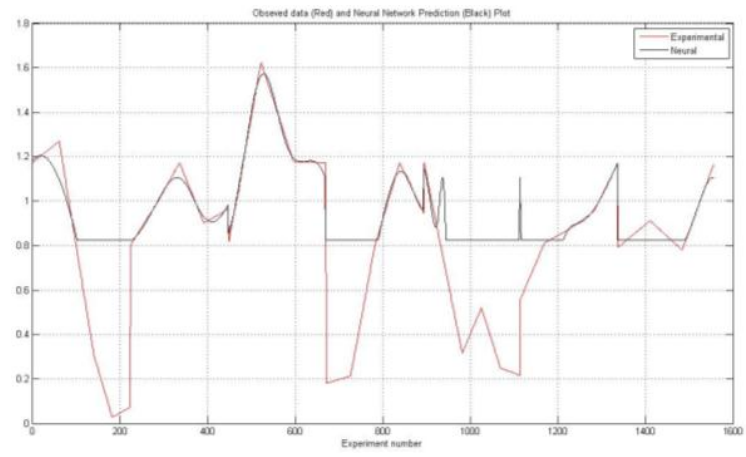

Figure 41: Neural response with layer transfer Function "logsig, poslin"

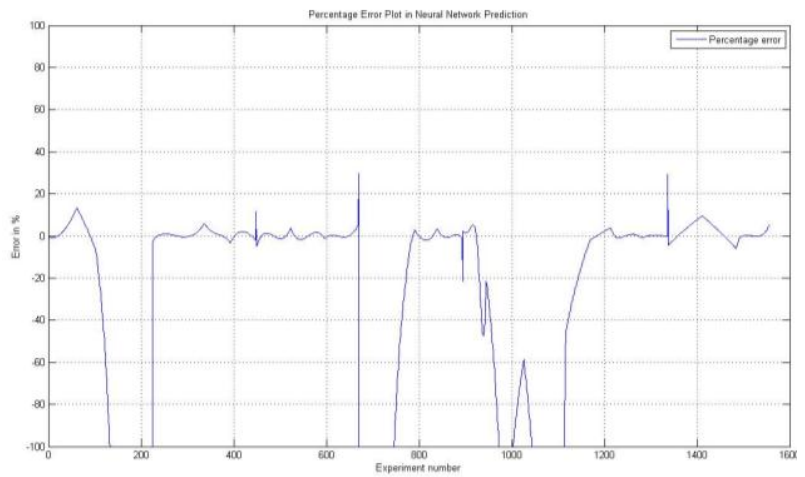

Figure 42: Percentage error with transfer Function "logsig, poslin"

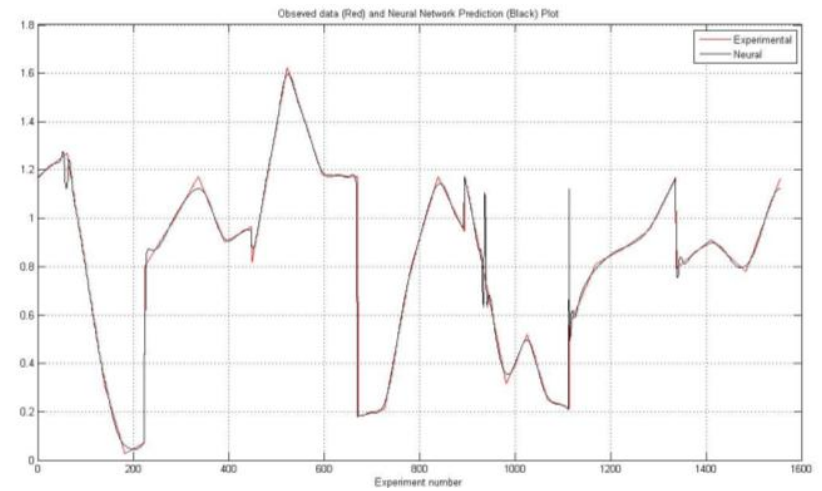

Figure 43: Neural response with Learn Function "learncon” 
International Journal of Chaos, Control, Modelling and Simulation (IJCCMS) Vol.2, No.3, September 2013

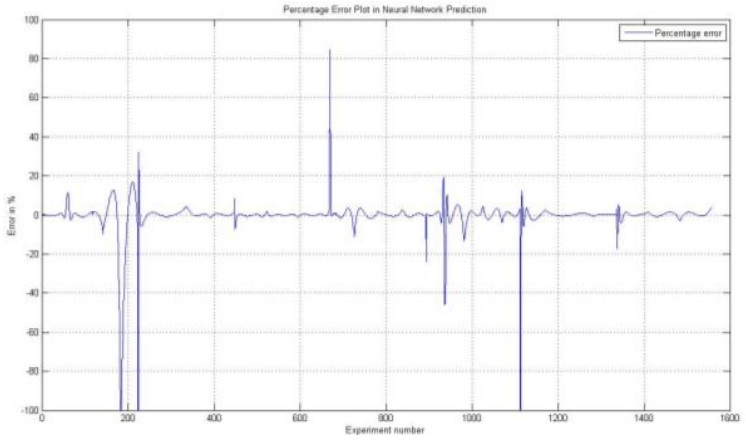

Figure 44: Percentage error with Learn Function "learncon"

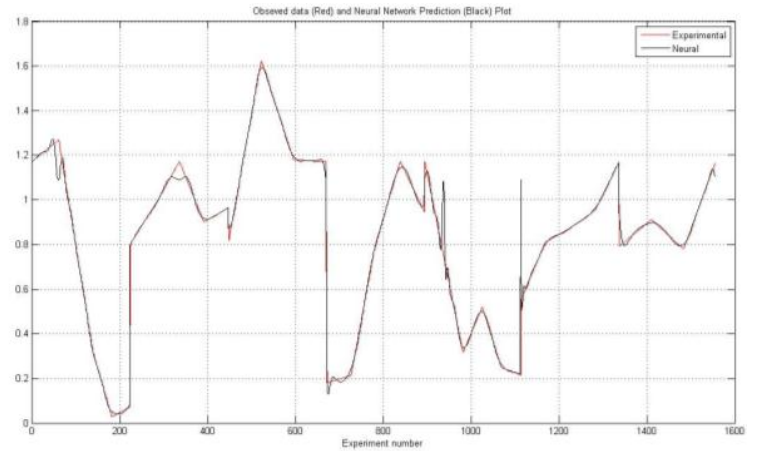

Figure 45: Neural response with Learn Function "learngd"

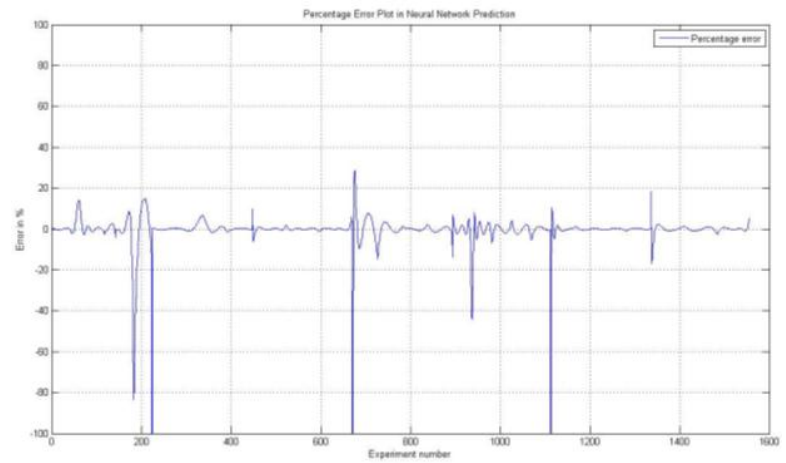

Figure 46: Percentage error with Learn Function "learngd"

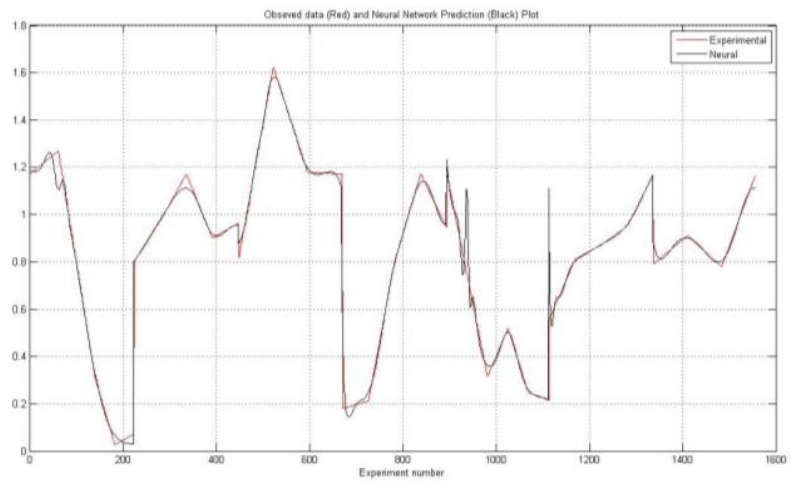

Figure 47: Neural response with Learn Function "learnh" 
International Journal of Chaos, Control, Modelling and Simulation (IJCCMS) Vol.2, No.3, September 2013

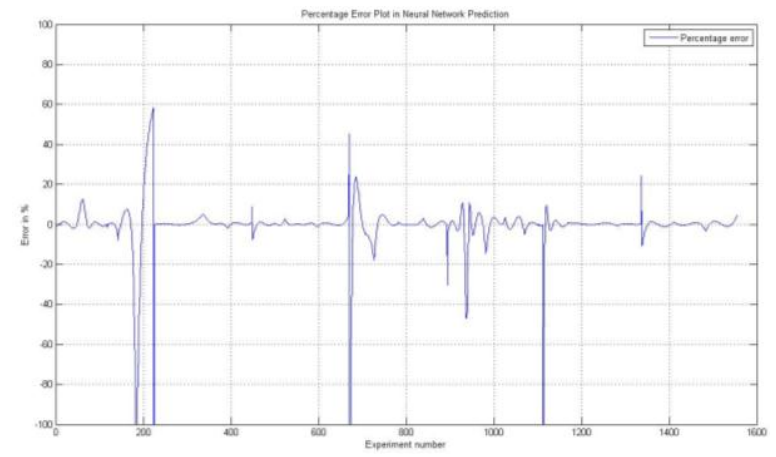

Figure 48: Percentage error with Learn Function "learnh"

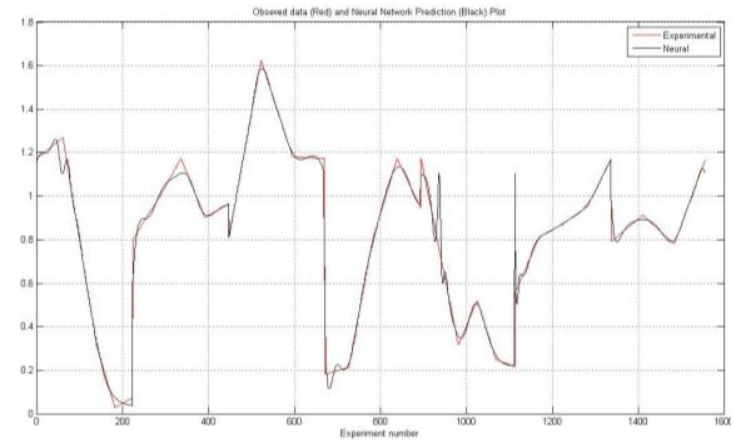

Figure 49: Neural response with Learn Function "learnk"

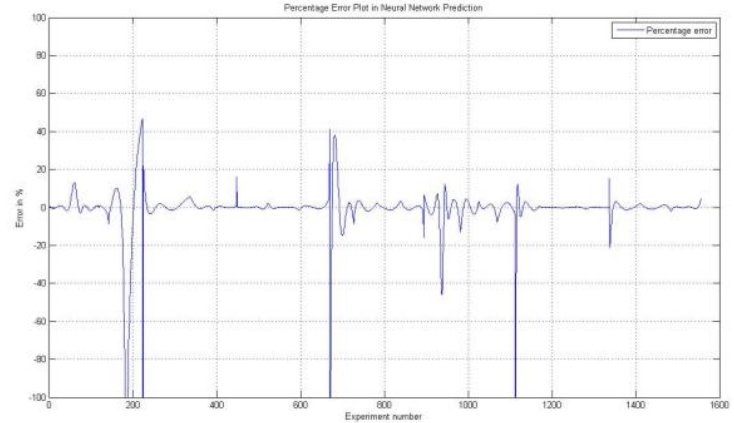

Figure 50: Percentage error with Learn Function "learnk"

\section{DiscuSSION OF RESUltS AFTER TRAINING}

\subsection{Effect of variation of number of neuron in hidden layer}

- Figure 8 to 10 shows that increase of number of neuron gives better prediction.

- But as the number goes to 200 it takes very large time to train the network

- Hence Layer size is limited to 100.

\subsection{Effect of variation training styles}

- Figure 10 to 14 gives the results when training styles are changed.

- The results are too bad with "trainb" \& "trainc"

- As a result it can be concluded that training styles affect the performance of network to great extent. 
- It is been observed that back propagation training functions are better for fitting function and the performance seems superior with "trainlm"

\subsection{Effect of variation of Performance Function}

- Figure 14 to 16 displays the results with change of performance function

- The change of performance function has shown little effect on prediction

- Performance function "sse" has shown better results.

\subsection{Effect of variation transfer function to hidden layer}

- Figure 16 to 24 shows the outcome when transfer function to hidden layers was changed.

- There are too many transfer functions to use and network has two hidden layers. Hence various combinations of these transfer functions were use to see the effect on performance.

- It is been observed that the outer most layer with linear transfer function "purelin" gives better results

- The combination of "logsig, tansig" transfer functions is found best for this case whereas "with "tansig, logsig" is worst.

\subsection{Effect of variation of Learning Function}

- Figure 24 to 28 put on view the results with variation of learning function.

- It clearly shows the is very mild effect of variation learning function on performance of network

- Out of those learning functions "learncon" \& "traingd" were very closed

- "learngd" is selected amongst them.

\section{CONCLUSION}

- The ANN simulation carried for HPFM operated Brick Making M/C gives satisfactory results

- The simulation is carried out is much exhaustive

- It includes almost all ANN parameters to see its effect on network performance

- The error in neural prediction much smaller and of the average of 5-10\%

\section{FUTURE SCOPE}

- Prediction of ANN model may be compared with the available empirical model.

- The best ANN model may be further used to develop another mathematical model.

- The ANN model could be validated through unseen data.

- This mathematical model then could be utilized to develop a physical controller. 


\section{REFERENCES}

[1] Modak J. P. and Askhedkar R. D. "Hypothesis for the extrusion of lime flash sand brick using a manually driven Brick making machine”, Bulding Research and Information U.K., V22,NI, Pp 4754, 1994

[2] Modak J. P. and Bapat A. R. "Manually driven flywheel motor operates wood turning machine", Contepory Ergonomics, Proc. Ergonomics Society annual convension13-16April, Edinburg, Scotland, Pp 352-357, 1993.

[3] Sohoni V. V., Aware H. V. and Modak J. P. “ Manual Manufacture of Keyed Bricks”, Building Research and Information UK, Vol 25, N6, 1997, 354-364.

[4] Modak J. P.’Design and Development of Manually Energized Process Machines having Relevance to Village/Agriculture and other productive operations, Application of manually energized flywheel motor for cutting of wood strip", Human Power, send for Publications.

[5] H. Schenck Junior "Theory of Engineering Experimentation", MC Graw Hill, New York.

[6] P. A. Chandak, "Modelling of manually driven brick making machine by use of ANN", M. Tech. Thesis, PCE, Nagpur

[7]. S. N. Shvanandam, "Introduction to Neural Network using Matlab 6.0", McGraw Hill publisher.

[8] Stamtios V. Kartaplopoulos, Understanding Neural Networks and Fuzzy Logics, IEEE Press

[9] Neural Network Toolbox ${ }^{\text {TM }} 7$ User's Guide R2010a, , Mathworks.com.

[10] Rudra Prtap, “Getting Started with Matlab7," Oxford, First Indian Edition 2006.

[11] A. R. Bapat, "Experimental Optimization of a manually driven flywheel motor", M.E. Thesis, VNIT, Nagpur.

[12] A. R. Bapat, Experimentation of Generalized experimental model for a manually driven flywheel motor", PhD Thesis, VNIT, Nagpur.

\section{Authors}

Pawan A. Chandak, Asstt Professor, Mechanical Engg, DMIETR, Wardha (MH), India ,Specilization: Artificial Neural Networks, Design and Fabrication, Vibration based predictive Maintenance.

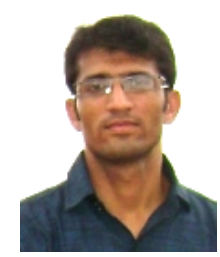

